\title{
HIGH DENSITY LIPOPROTEIN IN PREECLAMPSIA
}

\author{
BEGUM $Z^{1}$, AKHTER $S^{2}$
}

\begin{abstract}
Objective: The purpose of the study was to find the association between preeclampsia and serum HDL level.

Methods: This cross-sectional case-control study was conducted at Dhaka Medical College Hospital from January 2005 to December 2006. Pregnant women of gestational age $24-40$ weeks with preeclamptic toxemia were taken as cases, while pregnant women of gestational age 24-40 weeks but without preeclampsia were included as control. Pregnant women having systolic blood pressure $>140 \mathrm{mmHg}$, diastolic blood pressure $>90 \mathrm{mmHg}$, proteinuria with or without oedema were the enrollment criteria for the cases, while the pregnant women with both systolic and diastolic blood pressure within normal range were the selection criteria for the controls. Pregnancy with complications diabetes, renal insufficiency, hepatitis, antepartum haemorrhage and hydramnios were excluded from study. A total of 150 pregnant women of which 75 with preeclampsia and 75 with normal pregnancy were selected consecutively for the purpose of study. Data were collected by interview, observation, clinical examination and biochemical investigation and from the history sheet used for the patients.
\end{abstract}

Results: The result shows that cases and the controls were almost identical in terms age and

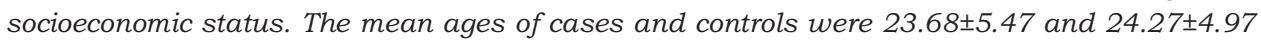
years respectively. Over two-third (68\%) cases and $74.7 \%$ of the controls belonged to lower socioeconomic class. The obstetric variables like parity, gravidity and gestational age were all homogeneously distributed between groups. The past obstetric histories like abortion/MR were observed to be almost alike between groups. A significantly higher proportion of cases (77.3\%) were found overweight and obese compared to their control counterpart. Anaemia was revealed to be significantly higher in case group (98.7\%) than that in control group (82.7\%) ( $p<$ 0.005). The risk of declining HDL below protective level (d" $30 \mathrm{mg} / \mathrm{dl}$ ) in cases was observed to be 28 times (OR=28; 95\% CI: 9.3 -90.5) higher than that in controls.

Conclusion: From the data it can concluded that the risk of developing atherosclerosis in preeclamptic women should be dealt with utmost care particularly in terms of dietary modification.

Key words: Preclampsia, HDL protective level, atherosclerosis.

J Dhaka Med Coll. 2011; 20(1) : 107-111.

\section{Introduction:}

Preeclampsia is a pregnancy specific disorder that presents major health problems for both mothers and babies. It is a major cause of maternal mortality, specially in developing countries, where it may account for $80 \%$ of maternal deaths. In a recent survey preeclampsia was found to be the second leading cause $(24.2 \%)$ of maternal death in Nigeria. ${ }^{1}$ Around $11 \%$ of maternal death is attributed to preeclampsia in Bangladesh. ${ }^{2}$

Preeclampsia is associated with increased risk of adverse maternal abruptio placentae, HELLP syndrome, eclampsia, and perinatal death. ${ }^{3}$ It is not only the cause of maternal mortality but is the leading cause of premature delivery and foetal growth retardation. It reduces uteroplacental blood flow and increases lipid peroxidation in the maternal circulation and in the placenta. ${ }^{4}$ It is a multi-system disorder that complicates $6 \%$ to $8 \%$ of pregnancies, with higher rates in women with preexisting hypertension, diabetes mellitus or previous history of preeclampsia. The majority of adverse pregnancy outcomes occurred in women who developed severe gestational hypertension or pre-eclampsia prior to 35 weeks of gestation or preexisting vascular disease. ${ }^{5}$

1. Dr. Zinat Begum, Registrar, Department of Obstetrics \& Gynaecology, Dhaka Medical College, Dhaka.

2. Prof. Sayeba Akhter, Department of Obstetrics \& Gynaecology, Bangabandhu Sheikh Mujib Medical University (BSMMU), Dhaka.

Correspondence: Dr. Zinat Begum, Department of Obstetrics \& Gynaecology, Dhaka Medical College, Dhaka. 
Although many active researches for years have been contemplated, the exact aetiology of this potentially fatal disorder remains unknown. ${ }^{6}$ The concept of altered lipid profile in preeclampsia is a newer one. Very few studies have been conducted to this end. In a study conducted in Spain by Gratacos ${ }^{7}$ and colleagues, it was found that the serum lipid profile was altered in preeclampsia. For example, free fatty acids and triglycerols were elevated in women who later developed preeclampsia. In a study of Peruvian women, HDL-cholesterol concentrations were 9\% lower in women with preeclampsia than that in control. ${ }^{1}$ Understanding the relationship between PET and HDL level might help us taking preventive measures to reduce the maternal morbidity and mortality. By far no such study has yet been conducted in the context of our country. An extensive study is, therefore, needed to find the association between PET and HDL level.

\section{Methods:}

This cross-sectional case-control study was conducted at Dhaka Medical College Hospital between January 2005 to December 2006. Pregnant women of gestational age between 24 - 40 weeks with preeclamptic toxemia were taken as cases, while pregnant women of gestational age between $24-40$ weeks and without preeclampsia were included as control. Pregnant women having systolic blood pressure $>140 \mathrm{mmHg}$, diastolic blood pressure > 90 $\mathrm{mmHg}$, proteinuria with or without oedema were the enrollment criteria for cases, while the pregnant women with both systolic and diastolic blood pressures within normal range were selected as controls. Pregnant women with diabetes, renal insufficiency, hepatitis, antepartum hemorrhage and hydramnios were excluded from study. A total of 150 pregnant women -75 with preeclampsia and 75 with normal pregnancy were selected consecutively for the study. In this study serum high density lipoprotein (HDL) above $30 \mathrm{mg} / \mathrm{dl}$ was considered protective against atheroma formation. Subjects with haemoglobin level below $12 \mathrm{gm} / \mathrm{dl}$ was termed as anemic and the subjects with BMI 25 or above $25 \mathrm{~kg} / \mathrm{M}^{2}$ were considered as overweight and obese.
Estimation of HDL-cholesterol was done by taking $2 \mathrm{ml}$ of venous blood from each subject. Serum was separated from the blood cells by centrifugation. Then $0.2 \mathrm{ml}$ of serum was mixed to $0.4 \mathrm{ml}$ of HDL-cholesterol reagent and was allowed to sit for 10 minutes at room temperature. Centrifugation was done for 10 minutes and $0.1 \mathrm{ml}$ of supernatant fluid was taken and mixed with $1 \mathrm{ml}$ cholesterol reagent and incubated for 10 minutes. Using a structured questionnaire, data (on variables of interest) were collected by interview, observation, clinical examination and biochemical investigation and from the historysheet used for the patients. Data were processed and analysed using SPSS version 11.5. Statistical analyses were done with help of descriptive statistics, Chi-square $\left(\div^{2}\right)$ Probability Test, Odds Ratio with 95\% confidence interval for the Odds Ratio. Data presented on categorical scale were compared between case and control group using Chisquare Probability Test. Risk of developing an event in case the group compared to the control group was estimated with the help of Odds Ratio. Level of significance for all analyses was set at 0.05 and p-value < 0.05 was considered significant.

\section{Results:}

Approximately $63 \%$ of the cases were in the range 20 - 30 years followed by $19(25.3 \%)$ below 20 years and $9(12 \%)$ above 30 years of age. In the control group about three-quarter $(74.7 \%)$ was in the age range $20-30$ years, $12(16 \%)$ below 20 years and $7(9.3 \%)$ above 30 years of age. The case and control groups were almost identical in terms of age $(\mathrm{p}=0.270)$ (Table I). The obstetric variables like parity, gravidity and gestational age were all homogeneously distributed between groups. The past obstetric histories like abortion/MR were observed to be almost alike between groups. However, 18.7\% of the cases had the histories of past PET compared to only $2.7 \%$ of the control group ( $p<$ 0.005). A significantly higher proportion of cases $(77.3 \%)$ were found to be overweight and obese compared to their control counterpart. Majority of the subjects in both the groups had anaemia. However, the presence of anaemia was revealed to be significantly higher in case 
group $(98.7 \%)$ than that in control group $(82.7 \%)$ $(p=0.001)$. More than three-quarter $(77.3 \%)$ of the cases was overweight and obese compared to $38.7 \%$ of the controls ( $<<0.05)$. Nearly twothird $(65.3 \%)$ of the cases had systolic blood pressure in the range $141-160 \mathrm{mmHg}$ followed $26.7 \%$ from $161-180 \mathrm{mmHg}$ and $8 \%>180$ mmHg. Over two-third (68\%) of the cases had diastolic blood pressure between $91-110$ $\mathrm{mmHg}$ and the rest (32\%) from $111-120 \mathrm{mmHg}$. Majority of the cases (81\%) exhibited severe albuminuria $(+++)$ and $19 \%$ moderate albuminuria $(++)$.

Table III compares HDL level between groups. Two-third $(66.7 \%)$ of the cases were found to have HDL 30 or below $30 \mathrm{mg} / \mathrm{dl}$ (below protective level) as opposed to only $6.7 \%$ of the controls (p $<0.001)$. The risk of declining HDL below protective level in cases was found to be 28 times (OR $=28 ; 95 \% \mathrm{CI}: 9.3-90.5)$ higher than that in controls.

\section{Table-I}

Comparison of age distribution between cases and controls

\begin{tabular}{lccc}
\hline Age (yrs)* & \multicolumn{2}{c}{ Group } & p- \\
& $\begin{array}{c}\text { Case } \\
(\mathrm{n}=75)\end{array}$ & $\begin{array}{c}\text { Control } \\
(\mathrm{n}=75)\end{array}$ & value \\
& $19(25.3)$ & $12(16.0)$ & \\
\hline 20 & $47(62.7)$ & $56(74.7)$ & 0.270 \\
$20-30$ & $9(12.0)$ & $7(9.3)$ & \\
$>30$ & $23.7 \pm 5.4$ & $24.2 \pm 4.9$ & \\
\hline
\end{tabular}

* Data were analysed using Chi-square $\left(\chi^{2}\right)$ Test; Figures in the parentheses indicate corresponding \%.

Table-II

Comparison of past obstetric history between groups

\begin{tabular}{lccc}
\hline Past obstetric & \multicolumn{2}{c}{ Group } & p- \\
history & Case & Control & value \\
& $(\mathrm{n}=75)$ & $(\mathrm{n}=75)$ & \\
\hline Past MR/abortion* & $15(20.0)$ & $12(16.0)$ & 0.581 \\
Past history of PET* & $14(18.7)$ & $2(2.7)$ & 0.270 \\
\hline
\end{tabular}

* Data were analysed using Chi-square $\left(\chi^{2}\right)$ Test; Figures in the parentheses indicate corresponding percentage.

\section{Table-III}

Comparison of medical conditions between case and control groups

\begin{tabular}{|c|c|c|c|}
\hline \multirow{2}{*}{$\begin{array}{l}\text { Medical } \\
\text { conditions* }\end{array}$} & \multicolumn{2}{|c|}{ Group } & \multirow{2}{*}{$\begin{array}{c}\mathrm{p}^{-} \\
\text {value }\end{array}$} \\
\hline & $\begin{array}{c}\text { Case } \\
(\mathrm{n}=75)\end{array}$ & $\begin{array}{l}\text { Control } \\
(\mathrm{n}=75)\end{array}$ & \\
\hline \multicolumn{4}{|l|}{ Level of haemoglobin } \\
\hline > 12 gm/dl (normal) & $1(1.3)$ & 13(17.3) & 0.001 \\
\hline$<12 \mathrm{gm} / \mathrm{dl}$ (anaemic) & 74(98.7) & $62(82.7)$ & \\
\hline \multicolumn{4}{|c|}{ BMI } \\
\hline$<25 \mathrm{~kg} / \mathrm{M}^{2}$ (normal) & $17(22.7)$ & 46(61.3) & $<0.001$ \\
\hline$>12 \mathrm{~kg} / \mathrm{M}^{2}$ & $58(77.3)$ & $29(38.7)$ & \\
\hline (Overweight or obese & & & \\
\hline
\end{tabular}

* Data were analysed using Chi-square $\left(\chi^{2}\right)$ Test; Figures in the parentheses indicate corresponding percentage.

Table-IV

Comparison of serum HDL between case and controlgroups

\begin{tabular}{|c|c|c|c|c|}
\hline \multirow[t]{2}{*}{ Level of $\mathrm{HDL}^{*}$} & \multicolumn{2}{|c|}{ Group } & \multirow{2}{*}{$\begin{array}{c}\text { Odds } \\
\text { Ratio } \\
(95 \% \mathrm{CI})\end{array}$} & \multirow{2}{*}{$\begin{array}{c}\mathrm{p}^{-} \\
\text {value }\end{array}$} \\
\hline & $\begin{array}{c}\text { Case } \\
(\mathrm{n}=75)\end{array}$ & $\begin{array}{l}\text { Control } \\
(\mathrm{n}=75)\end{array}$ & & \\
\hline $\begin{array}{l}<30 \mathrm{mg} / \mathrm{dl} \\
\text { (normal) }\end{array}$ & $50(66.7)$ & $5(6.7)$ & $28(9.3-90.5$ & 0.001 \\
\hline $\begin{array}{l}\text { > } 30 \mathrm{mg} / \mathrm{dl} \\
\text { (anaemic) }\end{array}$ & 25(33.3) & $70(93.3)$ & & \\
\hline
\end{tabular}

\# Data were analysed using Chi-square $\left(\chi^{2}\right)$ Test; Figures in the parentheses indicate corresponding percentage.

\section{Discussion:}

The present study demonstrated that two-third $(66.7 \%)$ of the cases had HDL 30 or below 30 $\mathrm{mg} / \mathrm{dl}$ (below protective level) as opposed to only $6.7 \%$ of the controls $(\mathrm{p}<0.001)$. The risk of declining HDL below protective level $(<30 \mathrm{mg} /$ dl) in cases was observed to be 28 times (OR = 28; 95\% CI: 9.3-90.5) higher than that in controls. The mean level of serum HDL in the present study was found to be significantly less in the preeclamptic patients $(29.49 \pm 2.81 \mathrm{mg} /$ dl) compared to their control counterpart $(40.77 \pm 4.75 \mathrm{mg} / \mathrm{dl})(\mathrm{p}<0.05)$. From the data of the present study, it appears that two-third of the preeclamptic patients were at 28 times higher risk of developing atherosclerosis compared to the uncomplicated pregnant 
women included in the study. In a study Dorothy and their associates ${ }^{1}$ found a mean level of cardioprotective HDL cholesterol was lower in the preeclamptic women compared with the control $(1.42$ and $1.64 \mathrm{mmol} / \mathrm{L}$ respectively, $\mathrm{p}<0.02)$ bearing consistency with present study.

High-density lipoprotein, a protective factor against atherosclerosis is oxidized in the subendothelial space. Oxidized HDL is not taken up by the macrophages and does not lead to formation of foam cells. However, the reverse cholesterol transport system is impaired by oxidative modification. ${ }^{8}$ The plasma level of HDL cholesterol is reportedly reduced in preeclampsia $^{9}$ which bears consistency with the findings of the present study.

Low level of serum HDL is the major pathogenic factor for coronary artery diseases. This is due to atherosclerotic changes of the arterial wall characterized by formation of atheromatous plaque by the deposition of cholesterol and cholesterol ester in the wall of the artery. So arterial wall becomes narrowed leading to myocardial infarction, thromboembolic diseases etc. HDL cholesterol facilitates reverse cholesterol transport by carrying excess, potentially harmful cholesterol from peripheral tissue to the liver, where it can be excreted. HDL cholesterol also regulates the exchange of protein and lipids between various lipoproteins. It acts as scavenger. So cholesterol cannot be deposited in the arterial wall and thus it prevents atherosclerotic changes of the arteries and reduces the risk of morbidity and mortality from coronary heart disease. A low level of high-density lipoprotein (HDL) cholesterol is, therefore, a risk factor for mortality from atherosclerotic cardiovascular disease. In a study conducted in Spain by Gratacos and colleagues ${ }^{7}$, it was found that women who had altered serum lipids like elevated free fatty acids and triglycerols in their early pregnancy later developed preeclampsia. In another study, HDL-cholesterol concentrations were 9\% lower in Peruvian women with preeclampsia than that in their control counterpart. HDL-cholesterol also regulates the exchange of protein and lipids between various lipoproteoins. ${ }^{1}$ In addition, it is involved in activating lipoprotein lipase, which releases fatty acids that can be oxidized by the per-oxidation pathway to provide energy. ${ }^{10}$ Low level of HDL-cholesterol may compromise the function of processes that involve this lipoprotein. In Portuguese women subject with precelampsia had a lower HDL cholesterol level compared with healthy pregnant women ${ }^{11}$ which further strengthens the findings of the present study. Understanding the relationship between preeclampsia and HDL level might help us taking preventive measures to reduce the risk of atherosclerosis. However, like most scientific study, the present study was not without limitations. Because of nonprobability/nonrandom sampling procedure the findings of the study must be interpreted with caution, particularly in case of generalization.

The present study intended to investigate the serum HDL level of preeclamptic patients found that two-third of the preeclamptic mothers had HDL level of 30 or below $30 \mathrm{mg} / \mathrm{dl}$ which is no longer considered protective to prevent the development of atheroma in the coronary arteries. It can, therefore, be concluded from the present study data that a sizable number of preeclamptic women might be at risk of developing atherosclerosis.

\section{References:}

1. Dorothy JV, Rina JP, Aliyu UE, George SM, Michael JC \& Robert HG. High density lipoprotein and homocystine levels correlate inversely in preeclamptic women in northern Neigeria. Acta Obstet Gynaecol Scand 2004; 83: 546-2.

2. Paul MC, Shakir AL, Zaman M. Anesthetic management of preeclampsia. JOPSOM 1994; 13(24): 102 .

3. Desvaux \& Haddad. Prevention of preeclampsia. Presse Med 2003; 32(33): 1559-65.

4. Wang $\&$ Walsh. Placental mitochondria as a source of oxidative stress in preeclampsia. Placenta 1998; 19: 581-6.

5. Sibai BM, Caritis S \& Hauth J. What we have learnt about preeclampsia. Semin Perinatol 2003; 27(3): 239-46.

6. Mandal NG \& Surapaneni. Regional anesthesia in preclampsia: advantages $\&$ disadvantages. Drug 2004; 64(3): 223-36. 
7. Gratacos E, Casals E, Gomez O, Llurba E, Mercader I, Cararach V, Cabero L. Increased susceptibility to low density lipoprotein oxidation in women with a history of pre-eclampsia. $\mathrm{Br} \mathrm{J} \mathrm{Obs}$ Gynaecol 2003; 110(4): 400-4.

8. Nagano Y, Arai H \& Kita T. High density lipoprotein loses its effect to stimulate efflux of cholesterol from foam cells after oxidative modification. Proc Natl Acad Sci 1991; 88: 645761.

9. Kaaja R, Tikkanen MJ, Viinikka L, Ylikorkala O. Serum lipoproteins, insulin and urinary prostanoid metabolites in normal and hypertensive pregnant women. Obstet Gynaecol 1995; 85: 3536.

10. McNamara DJ. Dietary fatty acid, lipoprotein and cardiovascular disease. Adv Food Nutr Res1999; 36: 253.

11. Belo L, Caslake M, Gaffney B, Santos-Silva A, Pereira-leite L \& Quinianiha A. Changes in LDLsize and HDL concentration in normal and preeclamptic pregnancy. Atherosclerosis 2002; 162: 425-32. 